\title{
Efeito de sanificantes no controle pós-colheita da podridão parda (Monilinia fructicola) e da podridão mole (Rhizopus stolonifer) em pêssegos
}

\author{
Fabiana Marchi de Abreu $^{1 *}$, Silvia Afonseca Lourenço ${ }^{1 * *}$, Eliane Bassetto ${ }^{1}$, Fabrício Packer Gonçalves ${ }^{1}$, Marise \\ Cagnim Martins $^{2} \&$ Lilian Amorim ${ }^{1 * *}$
}

${ }^{1}$ Departamento de Entomologia, Fitopatologia e Zoologia Agrícola, Escola Superior de Agricultura “Luiz de Queiroz”, Universidade de São Paulo, Cx. Postal 9, CEP 13418-900, Piracicaba, SP, fax (0xx19) 3434-4839, e-mail: fabianamabreu@hotmail.com *Bolsista da FAPESP-Processo 03/ 03967-8, **Bolsista CNPq, ${ }^{2}$ Instituto Biológico, Cx. Postal 70, CEP 13001-970, Campinas, SP.

Data de chegada:26/02/2006. Aceito para publicação em:24/11/2006.

\section{RESUMO}

Abreu, F. M., Lourenço, S. A., Bassetto, E., Gonçalves, F. P., Martins, M. C., Amorim, L. Efeito de sanificantes no controle pós-colheita da podridão parda (Monilinia fructicola) e da podridão mole (Rhizopus stolonifer) em pêssegos. Summa Phytopathologica, v.34, n.1, p.86-88, 2008

O objetivo desse trabalho foi avaliar o efeito in vitro e in vivo dos sanificantes cloreto de benzalcônio $\left(\right.$ Fegatex $\left.{ }^{\circledR}\right)$, biomassa cítrica (Ecolife $\left.{ }^{40 ®}\right)$ e ozônio no controle da podridão parda (Monilinia fructicola) e da podridão mole (Rhizopus stolonifer) em pêssegos das cultivares Aurora, Dourado e Flor da Prince. Cloreto de benzalcônio e biomassa cítrica, aplicados in vitro, ambos na concentração de $1000 \mu \mathrm{L} \mathrm{L}^{-1}$, inibiram totalmente o crescimento radial (micelial) de $M$. fructicola, porém nenhum deles foi eficiente no controle de $R$. stolonifer. Cloreto de benzalcônio aplicado de forma preventiva, na concentração de $3000 \mu \mathrm{L} \mathrm{L}^{-1}$, reduziu a podridão parda em frutos inoculados sem ferimentos. Quando aplicado de forma curativa em frutos não feridos esse produto foi eficiente em todas as concentrações testadas. Nenhum produto aplicado nos frutos de forma curativa foi eficiente no controle da podridão parda, quando a inoculação do fungo foi realizada através de ferimentos. Nenhum dos produtos foi eficiente no controle da podridão mole. O ozônio $\left(0,1 \mu \mathrm{L} \mathrm{L}^{-1}\right)$ não foi eficiente no controle das podridões parda e mole.

Palavras chave: controle alternativo, Prunus persica, ozônio, cloreto de benzalcônio, biomassa cítrica.

ABSTRACT

Abreu, F. M., Lourenço, S. A., Bassetto, E., Gonçalves, F. P., Martins, M. C., Amorim, L. Effect of sanitizing products on the postharvest control of brown rot (Monilinia fructicola) and soft rot (Rhizopus stolonifer) in peaches. Summa Phytopathologica, v.34, n.1, p.86-88, 2008

The purpose of this work was to study the in vitro and in vivo effects of the sanitizing products benzalkonium chloride $\left(\right.$ Fegate $\left.{ }^{\circledR}\right)$, citric biomass (Ecolife $\left.{ }^{40 ®}\right)$ and ozone gas on the control of brown rot (Monilinia fructicola) and soft rot (Rhizopus stolonifer) in peaches cultivars "Aurora", "Dourado" and "Flor da Prince". Benzalkonium chloride and citric biomass, both at $1000 \mu \mathrm{L} \mathrm{L} \mathrm{L}^{-1}$, completely inhibited the radial (mycelial) growth of $M$. fructicola, although none of them controlled $R$. stolonifer in vitro. The preventive use of benzalkonium chloride at $3000 \mu \mathrm{L} \mathrm{L}$ ${ }^{1}$ reduced brown rot in non-injured peaches. Benzalkonium chloride applied as curative in non-injured peaches was effective against M. fructicola at all concentrations. None of the products tested curatively was effective in preventing the development of brown rot when the fungus was inoculated over fruit injuries. None of the products was effective in controlling soft rot. Ozone gas at $0,1 \mu \mathrm{L} \mathrm{L}^{-1}$ was not effective in controlling brown or soft rots in peaches.

Additional keywords: alternative control, Prunus persica, ozone, benzalconium chloride, citric biomass.

O pêssego está sujeito a diversas doenças pós-colheita que acarretam perdas quantitativas e qualitativas. Patógenos como Monilinia fructicola e Rhizopus stolonifer, figuram entre os mais comuns agentes causais de doenças pós-colheita nessa cultura. Devido aos problemas decorrentes do desenvolvimento de resistência dos patógenos a fungicidas e, principalmente, pelos efeitos prejudiciais dos fungicidas ao meio ambiente e à saúde humana, tem sido atualmente preconizada a utilização de estratégias alternativas de controle que minimizem o uso de fungicidas (4).

O ozônio é um gás instável que se decompõe rapidamente, sendo considerado seguro para utilização em alimentos. Seu efeito no controle da podridão parda de pêssegos foi demonstrado por Palou et al. (4), somente para pêssegos inoculados com Monilinia fructicola em frutos armazenados por até 14 dias em câmaras com $0,3 \mu \mathrm{L} \mathrm{L}^{-1}$ de ozônio, em umidade e temperatura controladas. Em períodos mais longos de armazenamento ( 21 e 28 dias) e com outros patógenos comuns em pós-colheita, o produto não foi eficiente.

O cloreto de benzalcônio $\left(\right.$ Fegatex $^{\circledR}$ ) pertence ao grupo químico quaternário de amônio e apresenta uma elevada degradabilidade. Apresenta propriedades fungistáticas in vitro, inibindo o crescimento radial (micelial) de vários patógenos pós-colheita como Penicillium digitatum (1).

Ecolife ${ }^{40 \circledR}$ é um produto comercial originado de biomassa cítrica, ou segundo o fabricante, uma formulação aquosa heterogênea contendo polifenóis, flavonóides, fitoalexinas e ácidos orgânicos diluídos, que atuam como microbiostáticos, sendo recomendado para uso em campo e pós-colheita em diversas culturas (5).

Frente ao exposto, o presente trabalho teve como objetivo verificar 
Tabela 1. Efeito de cloreto de benzalcônio e biomassa cítrica no crescimento radial de Monilinia fructicola (oito dias) e Rhizopus stolonifer (três dias) em meio batata-dextrose-ágar.

\begin{tabular}{lcc}
\hline Tratamentos/ concentração & \multicolumn{2}{c}{ Crescimento radial (cm) } \\
$\left(\mu \mathrm{L} \mathrm{L}^{-1}\right)$ & M. fructicola & R. stolonifer \\
\hline Testemunha & $7,50 \mathrm{c}$ & $8,4 \mathrm{a}$ \\
Cloreto de benzalcônio 1 & $6,16 \mathrm{c}$ & $8,4 \mathrm{a}$ \\
Cloreto de benzalcônio 10 & $2,42 \mathrm{c}$ & $7,64 \mathrm{a}$ \\
Cloreto de benzalcônio 100 & $0,13 \mathrm{~b}$ & $7,88 \mathrm{a}$ \\
Cloreto de benzalcônio 1000 & $0 \mathrm{a}$ & $3,6 \mathrm{a}$ \\
Biomassa cítrica 1 & $6,23 \mathrm{c}$ & $8,4 \mathrm{a}$ \\
Biomassa cítrica 10 & $4,12 \mathrm{c}$ & $8,4 \mathrm{a}$ \\
Biomassa cítrica 100 & $0,93 \mathrm{~b}$ & $8,2 \mathrm{a}$ \\
Biomassa cítrica 1000 & $0 \mathrm{a}$ & $7,45 \mathrm{a}$ \\
\hline C.V. $(\%)$ & 40,67 & 10,89 \\
\hline
\end{tabular}

a eficiência de cloreto de benzalcônio, biomassa cítrica e ozônio no controle pós-colheita da podridão parda e da podridão mole em pêssegos.

Inicialmente, cloreto de benzalcônio e biomassa cítrica foram testados, in vitro, nas concentrações de $1,10,100$ e $1000 \mu \mathrm{L} \mathrm{L}^{-1}$ de i.a., com cinco repetições para cada concentração e patógeno testado. Os sanificantes foram adicionados em meio BDA fundente, o qual foi imediatamente colocado em placas de petri e, após resfriamento, um disco de micélio de $5 \mathrm{~mm}$ de diâmetro de cada fungo (M. fructicola e R. stolonifer) foi colocado no centro da placa de petri. As testemunhas consistiram da repicagem de disco de micélio para placas com BDA. As placas foram mantidas sob temperatura ambiente $\left(25 \pm 3^{\circ} \mathrm{C}\right)$ e as estimativas do crescimento radial das colônias foram feitas diariamente, medindo o comprimento da colônia em duas direções perpendiculares. O diâmetro máximo das colônias fúngicas nos meios de cultivo em BDA com os sanificantes foi comparado ao das colônias em BDA, pelo teste F.

Para o teste, in vivo, os pêssegos, Aurora, Dourado e Flor da Prince, foram desinfestados através da imersão em solução de hipoclorito de sódio $0,5 \%$ durante três minutos. A inoculação dos isolados foi realizada através da deposição de $20 \mu \mathrm{L}$ de suspensão de esporos, na concentração de $10^{5}$ esporos $\mathrm{mL}^{-1}$, sobre ferimentos de $0,3 \mathrm{~mm}$ de diâmetro. No experimento com M. fructicola, que possui a capacidade de penetrar o hospedeiro diretamente (3), utilizou-se, adicionalmente, a deposição de 20 $\mu \mathrm{L}$ da suspensão de esporos do fungo $\left(10^{5}\right.$ esporos $\left.\mathrm{mL}^{-1}\right)$ sobre a casca intacta do fruto.

Os produtos foram testados de forma curativa e preventiva com exceção do ozônio, que foi aplicado apenas como curativo. Nos testes realizados de forma curativa, os frutos foram inoculados com os respectivos fungos e, após quatro horas sob câmara úmida, foram imersos em solução de biomassa cítrica durante dois minutos nas concentrações de $0 ; 1000 ; 1500 ; 2000 ; 2500$ e $3000 \mu \mathrm{L} \mathrm{L}^{-1}$ de produto comercial ou em solução de cloreto de benzalcônio por quinze minutos nas concentrações de $0 ; 1000 ; 2000$ e $3000 \mu \mathrm{L} \mathrm{L}^{-1}$. Após cada tratamento, os frutos foram mantidos por sete a dez dias sob temperatura ambiente $\left(25 \pm 3{ }^{\circ} \mathrm{C}\right)$. Os frutos do tratamento com ozônio foram levados para a câmara de ozônio após a retirada da câmara úmida, onde permaneceram na concentração de $0,1 \mu \mathrm{L} \mathrm{L}$ ${ }^{1}$ do gás por quatro a sete dias, à temperatura de $24 \pm 1{ }^{\circ} \mathrm{C}$ e umidade relativa (UR) de $90 \pm 5 \%$. No teste preventivo, os frutos foram imersos nas soluções dos sanificantes nas mesmas concentrações utilizadas no teste curativo e a inoculação foi realizada após quatro horas. As testemunhas para ambos os patógenos e tratamentos consistiram na deposição de $20 \mu \mathrm{L}$ de água estéril contendo $10^{5}$ esporos $\mathrm{mL}^{-1}$ na casca da fruta, com e sem ferimento. $O$ delineamento foi inteiramente casualizado, sendo utilizados 10 frutos para cada concentração, tanto nos testes curativos como nos preventivos e 30 frutos para cada tratamento realizado na câmara de ozônio.

Os dados de incidência foram analisados por meio do teste não paramétrico de comparação de duas ou múltiplas proporções (6). Quando necessário, as proporções foram submetidas à transformação, utilizando as equações $\mathrm{Pi}=x /(n+1), \mathrm{Pi}{ }^{\prime}=(x+1) /$ $(n+1)$ e Pi" $=1 / 2[\operatorname{arcsenPi}+\operatorname{arcsenPi}$ '] de acordo com Zar (6), onde $x$ é o número de frutos totais de cada proporção, $n$ é o número de frutos doentes de cada proporção e Pi" é a proporção transformada.

Os resultados mostraram que, cloreto de benzalcônio e biomassa

Tabela 2. Incidência (\% de frutos doentes) de podridão parda (Monilinia fructicola) em pêssegos inoculados através de ferimento ou não, e de podridão mole (Rhizopus stolonifer) em pêssegos inoculados através de ferimento e tratados curativa e preventivamente com sanificantes.

\begin{tabular}{|c|c|c|c|c|c|c|}
\hline \multirow{3}{*}{ Tratamentos $\left(\mu \mathrm{L} \mathrm{L}^{-1}\right)$} & \multicolumn{4}{|c|}{ M. fructicola } & \multicolumn{2}{|c|}{ R. stolonifer. } \\
\hline & Tratamento & Curativo & Tratamento & Preventivo & Curativo & Preventivo \\
\hline & Com fer. & Sem fer. & Com fer. & Sem fer. & & \\
\hline Cloreto de benzalcônio 1000 & $60 \mathrm{a}$ & $0 \mathrm{a}$ & $30 \mathrm{~b}$ & $20 \mathrm{~b}$ & $80 \mathrm{a}$ & $80 \mathrm{a}$ \\
\hline Cloreto de benzalcônio 2000 & $70 \mathrm{a}$ & $0 \mathrm{a}$ & $0 \mathrm{a}$ & $10 \mathrm{~b}$ & $90 \mathrm{a}$ & $80 \mathrm{a}$ \\
\hline Biomassa cítrica 1500 & $80 \mathrm{a}$ & $20 \mathrm{c}$ & $80 \mathrm{c}$ & $10 \mathrm{~b}$ & $100 \mathrm{a}$ & $90 \mathrm{a}$ \\
\hline Biomassa cítrica 2000 & $50 \mathrm{a}$ & $20 \mathrm{c}$ & $30 \mathrm{~b}$ & $20 \mathrm{~b}$ & $100 \mathrm{a}$ & $60 \mathrm{a}$ \\
\hline Biomassa cítrica 2500 & $30 \mathrm{a}$ & $10 \mathrm{~b}$ & $50 \mathrm{~b}$ & $20 \mathrm{~b}$ & $90 \mathrm{a}$ & $50 \mathrm{a}$ \\
\hline Biomassa cítrica 3000 & $70 \mathrm{a}$ & $20 \mathrm{c}$ & $10 \mathrm{a}$ & $0 \mathrm{a}$ & $80 \mathrm{a}$ & $80 \mathrm{a}$ \\
\hline
\end{tabular}

*Valores seguidos por letras distintas, nas colunas, são significativamente diferentes entre si, ao nível de $5 \%$ de probabilidade pelo teste não paramétrico de comparação de múltiplas proporções. 
cítrica, na concentração de $1000 \mu \mathrm{L} \mathrm{L}^{-1}$, in vitro, inibiram totalmente o crescimento radial de $M$. fructicola, mas não inibiram o crescimento de $R$. stolonifer (Tabela 1), concordando com os resultados obtidos por Benato et al. (1).

Os produtos não foram eficientes no controle curativo da podridão parda, quando a inoculação dos frutos foi realizada, in vivo, através de ferimento (Tabela 2). Em frutos inoculados sem ferimentos, o cloreto de benzalcônio inibiu o desenvolvimento de podridão parda em todas as concentrações (Tabela 2), concordando com Benato et al. (1).

Cloreto de benzalcônio, na concentração de $3000 \mu \mathrm{L} \mathrm{L}^{-1}$, e biomassa cítrica, nas concentrações de 1000 e $3000 \mu \mathrm{L} \mathrm{L} \mathrm{L}^{-1}$, controlaram a podridão parda quando aplicados de forma preventiva em frutos inoculados sem ferimentos (Tabela 2). Estes resultados estão de acordo com os obtidos por Hanada et al. (2) e com os obtidos in vitro, neste trabalho.

Nos experimentos realizados para o controle de Rhizopus stolonifer nenhum dos produtos e formas de tratamento foram significativamente eficientes (Tabela 2).

A incidência de podridão parda em pêssegos (70\%) inoculados através de ferimentos e mantidos na câmara com ozônio não diferiu estatisticamente da testemunha $(76,7 \%)$. O tratamento também não foi eficiente nos frutos inoculados sem ferimentos $(20 \%$ na testemunha e $13 \%$ em frutos tratados). A incidência de podridão mole em pêssegos mantidos na câmara com ozônio foi estatisticamente igual à incidência de doença em pêssegos mantidos em câmara com atmosfera normal, 76,67 \% e 78,3\%, respectivamente concordando com os obtidos por Palou et al. (4). O ozônio $\left(\mathrm{O}_{3}\right)$, portanto, não foi eficiente no controle das podridões parda e mole em pêssegos, na concentração de $0,1 \mu \mathrm{L} \mathrm{L}^{-1}$.

\section{AGRADECIMENTO}

Ao Prof. Dr. Ângelo P. Jacomino do Departamento de Produção Vegetal da ESALQ pelo apoio a este trabalho e à FAPESP (02/129280 e 03/03967-8) pelo apoio financeiro.

\section{REFERÊNCIAS BIBLIOGRÁFICAS}

1. Benato, E. A.; Sigrist, J. M. M.; Perrone, S. Efeito de um composto de cloretos de benzalcônio sobre o crescimento micelial de fungos causadores de podridões pós-colheita em frutas. In: Congresso Paulista de Fitopatologia, 21, 1998, Botucatu. Anais ... Campinas: Fundação Cargil, 1998. p. 123.

2. Hanada, R.E.; Gasparotto, E.; Pereira, J.C.R. Eficiência de desinfestantes na erradicação de conídios de Mycosphaerella fijiensis aderidos à superfície de bananas. Fitopatologia Brasileira, Brasília, v. 29, n. 1, p. 94-96, 2004.

3. Martins, M.C.; Betti, J.A.; Leite, R.M.V.B.C.; Amorim, L. Doenças das rosáceas de caroço. In: KIMATI, H.; AMORIM, L.; REZENDE, J.A.M.; BERGAMIN FILHO, A.; CAMARGO, L.E.A. (Ed.). Manual de Fitopatologia: doenças das plantas cultivadas, São Paulo: Agronômica Ceres, 2005; v. 2; cap. 62, p. 545-557.

4. Palou, L.; Crisosto, C.H.; Smilanick, J.L.; Adaskaveg, J.E.; Zoffoli, J.P. Effects of continuous 0.3 ppm ozone exposure on decay development and physiological responses of peaches and table grapes in cold storage. Postharvest Biology and Technology, Amsterdam, v. 24, p. 39-48, 2002.

5. Quinabra. Ecolife ${ }^{40}$ - Estimulando as plantas a produzir suas próprias defesas. São José dos Campos, s. d. 14 p. (Boletim Técnico).

6. Zar, J.H. More on dichotomous variables. In: ZAR, J.H. Biostatistical analysis. Englewood Cliffs: Prentice-Hall, 1999. cap. 10 , p. 516-570. 